\title{
An analysis of Great Britain's long-term stores of energy
}

Dr Grant Wilson ${ }^{a, b}$, Noah Godfrey ${ }^{a, b}$, Dr Adriano Sciacovelli ${ }^{b}$, Dr Jonathan Radcliffe ${ }^{b}$, Dr Yongliang Li b, Professor Yulong Ding ${ }^{b}$

a) Energy Data Analytics Group, School of Chemical Engineering, The University of Birmingham

b) Birmingham Centre for Energy Storage, The University of Birmingham

\section{Abstract:}

Great Britain's stocks of coal, natural gas, and petroleum have seen major changes to the levels of stored energy over the years 2005 to 2019, a reduction of 200 TWh (35\%) from 570 TWh to 370 TWh. The transformation of its electrical system over this timeframe saw a reduction in coal generation, leading to a corresponding reduction of the levels of stockpiled coal of $85 \mathrm{TWh}(68 \%)$, partially offset by an increase in the stocks of biomass for electrical generation. The reduction in natural gas storage of 24 TWh (44\%) was primarily due to the closure of Britain's only long-term seasonal natural gas storage facility in January 2018. This was partially offset by the construction of medium-term natural gas storage facilities and the use of LNG storage in the years preceding its closure. For stocks of crude oil and oil products the reduction was 35 TWh (21\%), linked to the overall reduction in demand.

\section{Introduction}

For most countries, the transition to a net-zero economy will see a wholesale shift of their sources of primary energy. The energy networks that connect primary energy supply and end user demand and the stores of energy that provide the buffers between supply and demand will need to adapt. In particular, the types, scale and locations of stored energy is likely to change, with a trend towards increased levels of distributed energy storage such as battery and thermal energy stores although this is subject to a high degree of uncertainty (Dodds and Garvey, 2016). How a change of primary energy sources and their associated networks will impact the need for traditional larger strategic centralised stores of energy is an open research and policy question for many countries. The question of what levels of centralised strategic stores of energy are needed in a low-carbon energy system to provide security of supply, particularly over longer timeframes, is a complex research question. So too is understanding whether greater levels of distributed storage will complement or compete with larger centralised stores.

The creation of synthetic fuels (Power-to-X and electrofuels) has attracted greater levels of research interest from a number of different perspectives (Kötter et al., 2016; Ziegler et al., 2019; Lewandowska-Bernat and Desideri, 2018; Chen et al., 2019; Nayak-Luke and Bañares-Alcántara, 2018; Dawood et al., 2020; Götz et al., 2016; Chen et al., 2009) as the levels of renewable energy generation as primary sources of energy increase in many countries around the world, and the realworld challenges of integrating these becomes more evident. Although there are pronounced seasonal variations with solar and wind generation for a Northern European energy system such as Great Britain, the levels of long-term seasonal stored energy are significantly influenced by the levels of security of supply that the country feels it needs. This can be viewed as trade-off between energy that has have a higher degree of availability during energy supply chain shocks, and the seasonal availability of primary energy from a basket of different sources. Part of the need for long-term storage can be conceived as an insurance policy, that a country has in preparation for events that are uncommon but nonetheless expected, and that it perhaps hopes only to use infrequently.

Historically, energy systems have been 'managed' by a range of regulations and market forces to provide an appropriate level of security from supply disruptions. The focus has been on having enough energy available if and when a loss of supply perhaps occurred, and this driver for long-term energy storage would seem to continue to be valid. However, an additional driver in the future is 
from the accommodation of greater levels of renewable energy, where there will be a growing need to store the 1-10s of TWhs of electrical generation that become available due to the instantaneous surplus of generation vs demand. Curtailing amounts of renewable generation may be a cost effective means to balance the electrical network up to a certain level, but if TWhs of available generation are being curtailed at certain times of year, even though there will be a likely deficit at other times of year, then long-term storage of energy has an additional role to play.

This article presents evidence of the changing pattern of longer-term stores of energy in Great Britain. These stores have served Great Britain well, with few shortages or widespread supply chain disruptions of primary energy. Here we detail the historical scale of change of the long-term stores of energy within Great Britain from 2005 to 2019, and explore why this may have been the case.

\section{Market drivers for long-term energy storage in Great Britain}

All forms of storage have an energy penalty, where the useful energy returned is not as much as the amount of energy originally put into storage. Even storing fuels that have low losses of useful energy over time, there is an energy penalty in terms of shifting/transporting the fuels in and out of storage, and the energy embedded in the infrastructure to store the fuels themselves. These might be negligible in comparison to the overall amount of energy stored, but nonetheless reinforces the point that there is always an energy penalty.

If it is accepted that storing energy is always associated with an energy penalty, then it also follows that there has to be a benefit from the storing of energy that outweighs the disbenefit of the loss of useful energy.

The market need or a regulatory requirement that incentivises organisations to provide energy storage will be different for various countries. For Britain, the change in natural gas stocks and coal stockpiles is not mandated by regulation, so the levels of these fuels in storage is determined by various market forces. For coal, the stocks reported in this article include the stockpiles of coal for electrical generators that help to manage the risk of running out of fuel to create the electricity. This provides a limited security of supply to the coal operator to be able to generate when it is profitable to do so, but is also thought to be a response to the price of coal by storing more when prices are cheaper as a market hedge against seasonal price variations. When aggregated together, this selfinterest at the level of an individual generator also provided the nation with a meaningful security of supply for part of its electrical generation.

To the authors' knowledge, there has been no centrally coordinated effort to plan for long-term storage for coal or natural gas since Britain's liberalisation of its energy systems. However, there is legislation surrounding the levels of liquid fuels to be kept in storage due to its membership of the European Union and the IEA.

Overall, the aim of long-term energy storage is to provide a means to decouple the initial harvesting of primary energy or energy products from eventual final energy use in time and location. This provides a primary benefit in terms of a security of supply, so that disruptions to energy supply chains do not have a disproportionate effect in terms of the economy and people's wellbeing.

The scale of Britain's primary energy demand varies seasonally between about 3 TWh per day in the summer to around 7 TWh per day in the winter. It is uncertain whether the long-term storage of energy will need to be in the 100s of TWh scale, or whether the impact of greater levels of renewable generation within the Britain's land and maritime boundaries will reduce the need for this.

If Great Britain looks to market frameworks underpinned through strong regulation to manage its future energy systems, these will ultimately determine the levels of its long-term energy storage. A balance between the cost of storing energy, versus the cost of running low of energy is one that 
policy makers will continue to focus on as energy systems transition to low-carbon forms of generation with low-carbon forms energy vectors and storage.

\section{The stores of energy in Britain}

\section{Crude oil and oil products}

Liquid fuels in the form of crude oil and oil products have had a special focus under legislation since the UK's 1976 Energy Act that provides legislation for a Minister to require certain companies to hold minimum levels of oil stocks. This is part of the UK's commitment to international agreements that are detailed in the 'UK Emergency Oil Stocks' document (DECC, 2015).

This is a unique position for crude oil and oil products as liquid fuels, as gaseous and solid fuels are not subject to a similar recognition and regulation of minimum levels of stock. The cost of having these levels of stored energy is passed through to final consumers and is ultimately simply a part of the overall cost of the fuel. Crude oil and liquid fuels are predominantly used in the transport sector, and therefore the legislation can be seen as reducing the risk to transport systems within the UK from a significant or sustained crude oil or oil products supply chain shock.

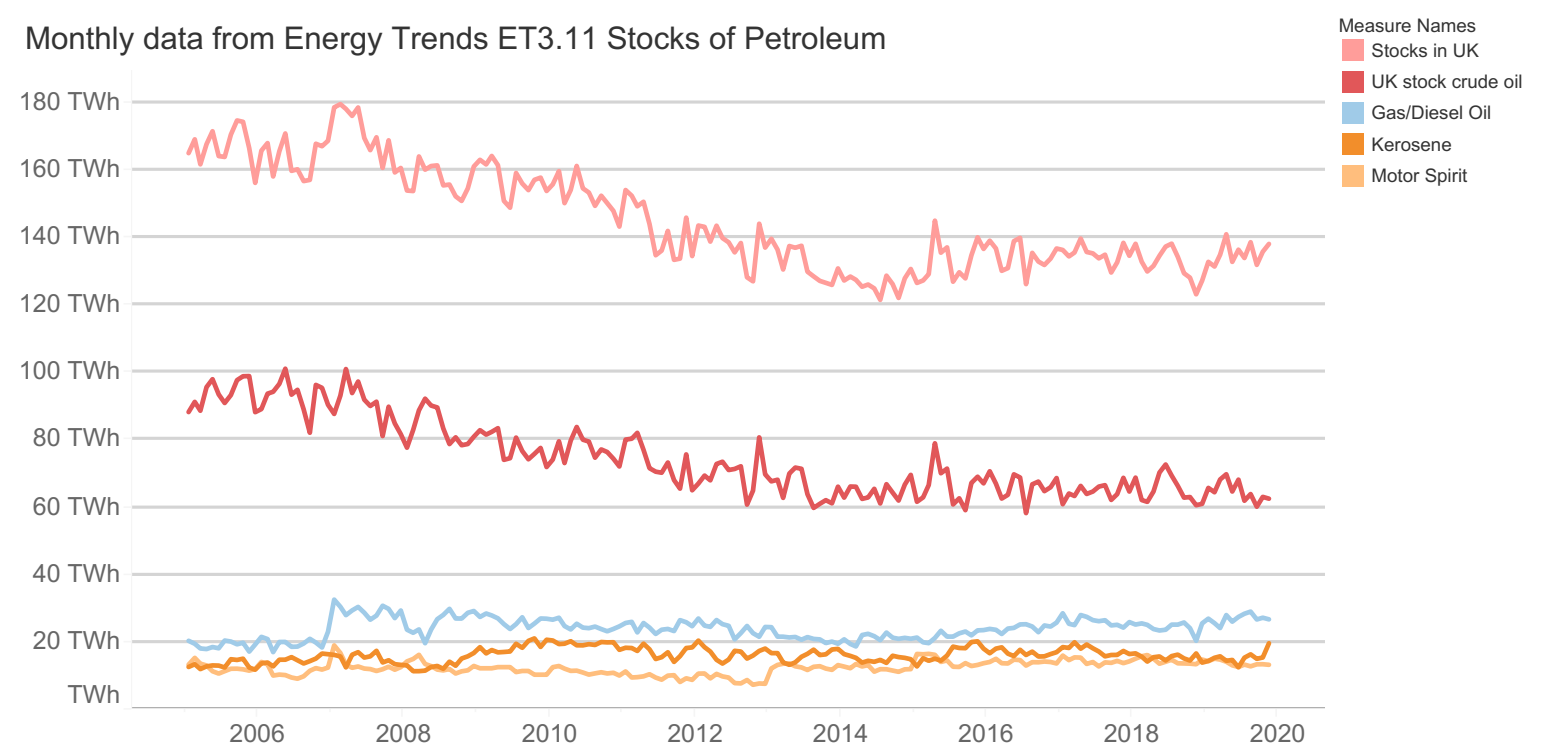

Figure 1 - Chemical energy contained in crude oil and oil products. Calculated from Stocks of petroleum (ET 3.11) (BEIS, 2019a), monthly data.

The spreadsheet containing the data for Figure 1 (ET 3.11) states 'The UK continues to hold stocks sufficient to cover two months of consumption, which is broadly in line with international agreements' (BEIS, 2019a). The values are reported in 1000s of tonnes, and converted into an energy content using a gross calorific value of $45.7 \mathrm{GJ}$ per tonne (0.0127 TWh per 1000 tonnes) (DUKES A.1A.3, 2019)

Figure 1 shows a trend from 2006 to 2014 for the reduction in UK held crude oil stocks, which has broadly stabilised around $65 \mathrm{TWh}$. When oil products are included, this value doubles to $135 \mathrm{TWh}$.

Coal

Figure 2 shows the start-of-year values for coal stocks in TWh over a much longer 49-year time period from 1971 to 2019 . These values are calculated using a gross calorific value for coal of $26.5 \mathrm{GJ}$ per tonne (0.0074 TWh per 1000 tonnes) (BEIS, 2018). The tonnage data is from BEIS Digest of UK Energy Statistics DUKES 2.1.1 - Coal production and stocks, 1970 - 2018 (BEIS, 2019b) 


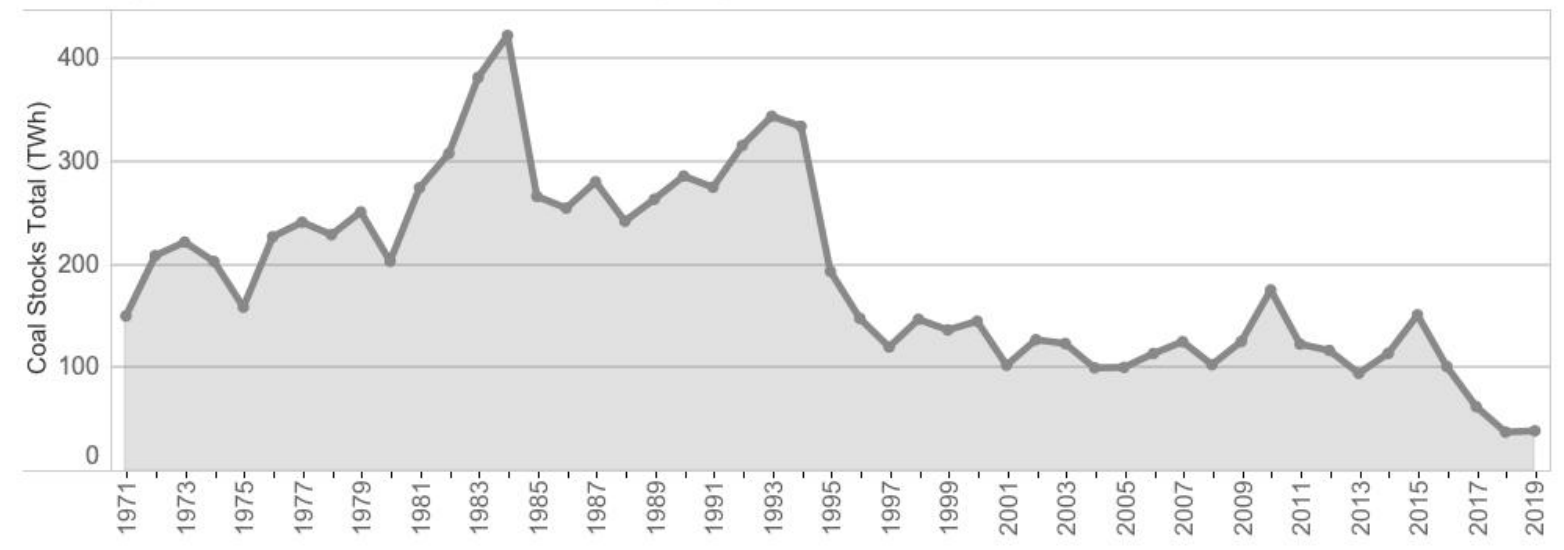

Figure 2 - UK start of year coal stocks 1971-2019 (TWh)

Figure 2 shows a step change of stockpiled coal from 1995 through to 2016 to around 100-150 TWh of energy. Prior to this, most values were within the 200-300 TWh range. This is due to the shift from coal to natural gas generation that happened through the 1990s, with a corresponding reduction in the amount of coal stocks. It may also be influenced by the greater levels of imported coal over this period too, and the shift from a centrally planned coal supply chain with indigenously produced coal, to a market based international supply chain. The drop in coal generation from 2015 was due to a number of factors including a meaningful carbon price (Wilson and Staffell, 2018).

More detailed monthly coal-stocks data are available from 1995 onwards from BEIS Energy Trends ET2.6 - Coal consumption and coal stocks (BEIS, 2019c). End of month TWh values are shown in Figure 2(a) and a further calculation of months of coal for electricity generation is shown in Figure 2(b). This calculation is the amount of stock for electrical generation at the end of the month (a subset of the total amount of coal stocks) divided by the demand from electrical generation over that month. The years $2015-2019$ are not shown, as the reduction in coal generation has disproportionally increased the number of months of coal generation that stockpiles could accommodate.

Figure 3a shows a seasonality to coal stocks that is not apparent from the start of year data in Figure 2. This allows coal generators to have significant buffers of energy to ride through supply chain disruptions during winter. Generators would build up stocks of coal in the summer, to be able to draw upon these (as well as ongoing supplies) during the winter period when demand increased for electricity. There would also likely be a seasonal price driver too, where the cost of purchasing and storing the coal was more than offset by the reduced price of coal in the summer. Regardless of the underlying priorities of each individual coal generating company over the period, the data makes it clear that 100s of TWhs of stored energy in the form of coal was not uncommon. Given the phase out of coal generation in the UK, coal stockpiles are likely to drop to around $10 \mathrm{TWh}$ to provide a feedstock/energy buffer for coke ovens and other industry rather than any stored for electrical generation. 
(a) Total UK coal stocks in TWh

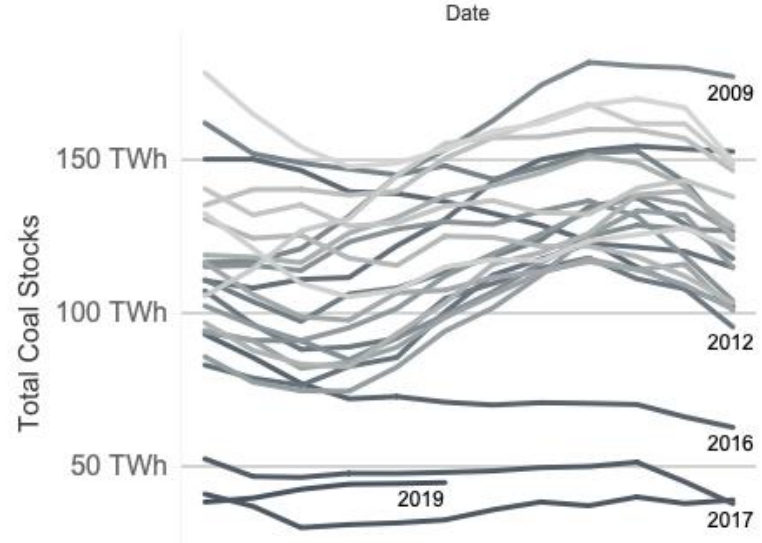

TWh (b) Months of coal for electricity generation

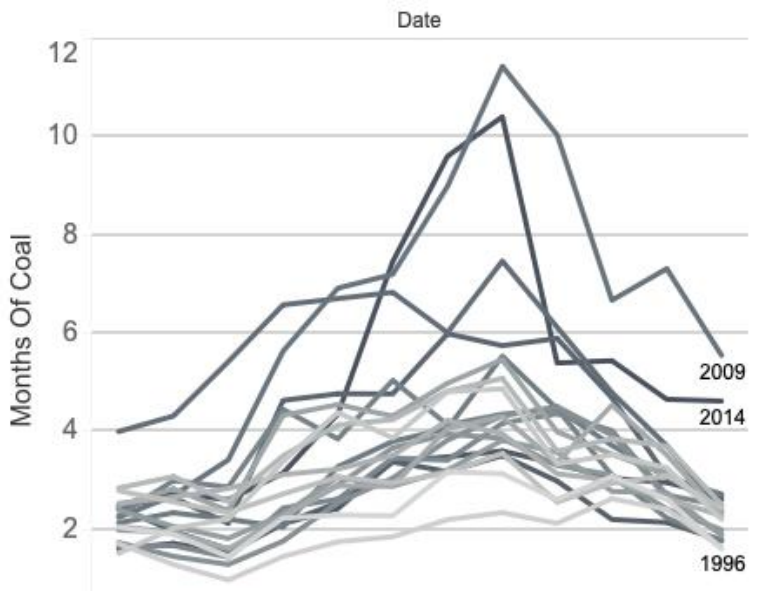

0

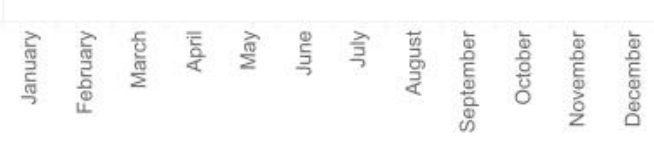

Figure 3 - Monthly values for UK coal stocks since 1995

Coal provides a simple, economic and relatively safe means of storing TWhs of energy within the UK's national boundaries, but its unabated combustion is incompatible with climate change targets. Capturing the carbon from coal may extend its use for industry (and thus stockpiles of coal) but given recent trends in the cost of weather dependent renewable sources of electrical generation (BEIS, 2019d, 2019e), it is challenging to see coal generation with CCS being developed commercially in the UK.

\section{Nuclear}

The amount of nuclear fuels 'stockpiled' for civil nuclear reactors is not known. Based on the assumption that there as least a year's worth of nuclear fuel within Great Britain's borders. In 2018 the electricity generated from nuclear totalled 65 TWh (BEIS, 2019f)(BEIS, 2019g), and assuming a nuclear plant efficiency of $40 \%$ (BEIS, 2019f) gives an annual total of over 160 TWh of fuel required. This is broadly similar to the published values from BEIS of the 'fuel used' that is displayed in million tonnes of oil equivalent (BEIS, 2019g). Using these figures and a value of $45.7 \mathrm{GJ}$ per tonne of oil (0.0127 TWh per 1000 tonnes), the values for 'fuel used' in 2005 was 217 TWh and in 2018 it was 178 TWh.

There is a high degree of uncertainty surrounding the level of stockpiled nuclear fuel within Great Britain as the values are not in the public domain. Another area of uncertainty is that the operators of Britain's nuclear fleet are global companies, and are likely to hold stocks at a company level; but whether these are physically within Britain's national boundaries or kept elsewhere to be able to be transported to Britain is not known.

\section{Natural Gas}

Natural gas storage in Britain is categorised under four types of gas storage: short, medium, long, and Liquified Natural Gas storage (LNG). The only facility ever to be categorised under 'long' storage is denoted by the grey part of Figure 4 and was the Rough seasonal gas storage facility. This suggests this repurposed gas field had an operational capacity to contain around $40 \mathrm{TWh}$ of chemical energy. Since its closure as a storage facility in January 2018 , Rough's storage capacity is no longer available. The total capacity of gas storage has therefore reduced from circa 65 TWh in 2014 to 31 TWh of chemical energy in 2019. 17.5 TWh of this remaining storage capacity is provided by high pressure 
onshore caverns, and 13.5 TWh is provided by LNG storage. Looking at the demand for natural gas, the cold weather event on the $1^{\text {st }}$ of March 2018 gave a peak daily gas demand of $4.4 \mathrm{TWh}$. The overall capacity of natural gas facilities therefore approximates to 7-days of peak natural gas demand at peak daily demand (although the output capacity of storage facilities could not achieve this maximum rate of discharge). The $1^{\text {st }}$ of March 2018 was interesting for a number of reasons, not least that it happened late in the heating season when the expectation would be that the stores of natural gas had already been run down. This was indeed the case, with about $15 \mathrm{TWh}$ of chemical energy being stored when Britain was subjected to the cold weather event.

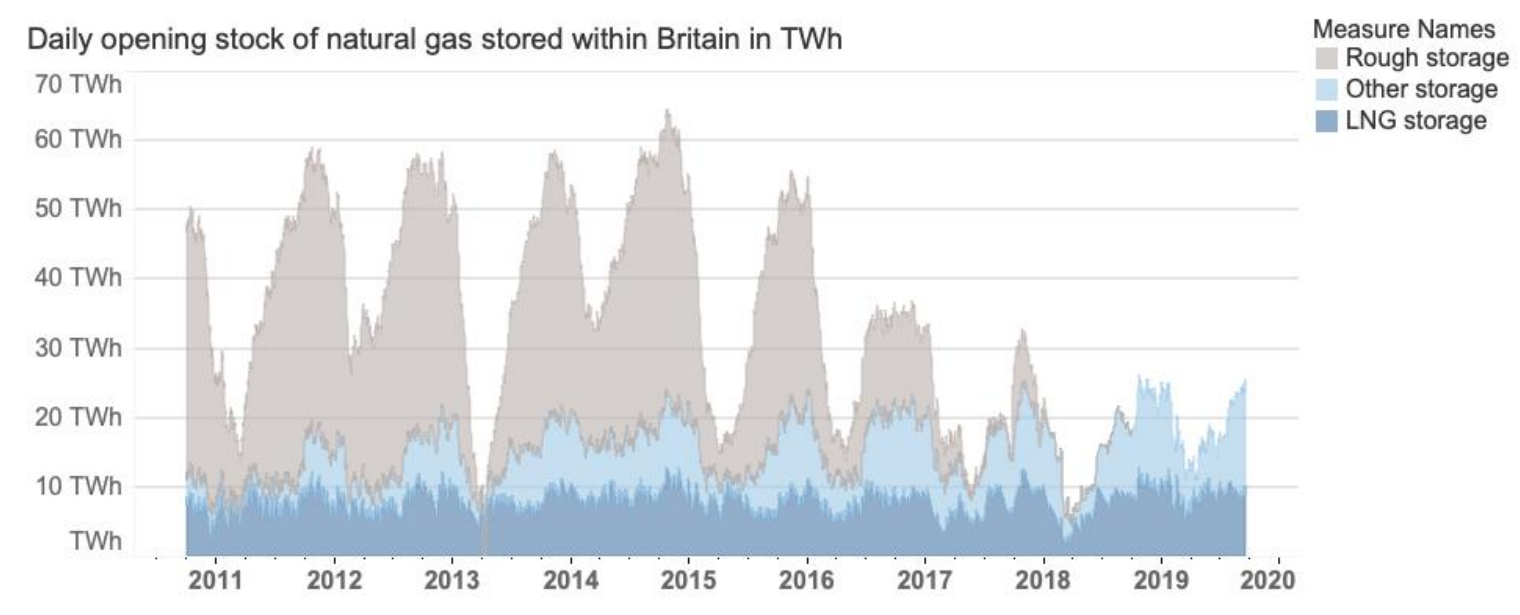

Figure 4 - Daily opening stock of natural gas stored within Britain in TWh

\section{Biomass}

Biomass as a primary energy feedstock for electrical generation has increased from a net electrical supply of 5.5 TWh in 2012 to 18 TWh in 2018 (BEIS, 2019h). A significant part of this increase has been the shift over from coal to wood pellets in the Drax power plant in Yorkshire. The in-country supply chain for Drax has a capacity of 500,000 tonnes of wood pellets; $8 \times 25,000$ tonne silos at the Port of Immingham (Drax, 2018), and 300,000 tonnes (Drax, 2016) of wood pellets in domes on the Drax site. With an estimated gross calorific content of $18.3 \mathrm{GJ}$ per tonne (BEIS, 2018), this equates to a possible 2.5 TWh of energy in pellets in Britain for the Drax supply chain alone. The changes to the amount of stored wood pellets over monthly levels is not known, nor is the amount from other wood pellet generators' supply chains. Therefore, an estimate of 3 TWh of chemical energy in wood pellets in country is estimated.

\section{Battery storage in Electric Vehicles}

As of September 2019, the quantity of storage in registered Plug-In capable Electric Vehicles is 5.8 GWh (Table 1); this is a total of pure Electrical Vehicles (EV) and Plug-in Hybrid Electric Vehicles (PHEV). The Department for Transport reported 221,000 Plug-In capable cars registered in the third quarter of 2019, a 60,000 car increase from the similar point in 2018 (DfT, 2019). Since 2014 registrations of EVs have increased tenfold, with the storage capability increasing to the same degree.

The manufacturer BMW had the largest number of registrations of EVs or PHEVs in 2019 Q3 with nearly 50,000, with Mitsubishi and Nissan following in second and third. However, when comparing the overall battery capacity, Tesla came out on top with $28 \%$ of the storage capacity for the UK, from only $9 \%$ of the registrations. Tesla EVs typically have $100 \mathrm{kWh}$ batteries, much higher than the typical battery size in Plug-In Hybrid EVs which dominated the registrations in 2019 Q3. The storage capacity of each model of EV was taken from the manufacturers' website. 
The proportion of EVs of the total number of licensed vehicles is $0.6 \%$, and yet the raw storage capacity at $5.8 \mathrm{GWh}$ is already nearly half of the Dinorwig Pumped Storage scheme (Yohe and Clarke-Johnson, 2019). The full capacity of EV batteries is unlikely to be utilised on a daily basis, particularly for the larger sized batteries, but the scale is indicative of a shift that is currently underway. In comparison to the previous types of energy storage considered in this article, a contrasting feature of EV storage is its highly distributed nature and therefore its potential to support parts of the electrical grid at a local level (Amamra and Marco, 2019). This is dependent on two main underpinning factors; the technology that would allow EV batteries to support local networks and the willingness of the battery owner to allow this to happen (Noel et al., 2019).

With the rate of adoption in this technology increasing, the quantity of storage available within EVs is set to increase rapidly from 2020 to 2030 . Using a similar average battery capacity to EV registrations ( $0.6 \%$ of the total vehicles and $5.8 \mathrm{GWh}$ of storage = an average of $27.5 \mathrm{kWh}$ ); at $100 \%$ market saturation this would equate to 0.9 TWh of storage. However, with continued innovation and economies of scale the costs of battery packs decreasing and the energy density of these increasing, there will be a continued shift to pure EVs compared to PHEVs (Nykvist et al., 2019). With other forms of electrified transport, this will likely shift the storage capacity into TWhs. For comparison the 0.9 TWh capacity is broadly similar in scale to the average daily electrical demand for Britain in 2019.

\begin{tabular}{|c|c|c|c|c|c|c|}
\hline & $\begin{array}{l}2014 \\
\text { Q3 }\end{array}$ & $\begin{array}{l}2015 \\
\text { Q3 }\end{array}$ & $\begin{array}{l}2016 \\
Q 3\end{array}$ & $\begin{array}{l}2017 \\
\text { Q3 }\end{array}$ & $\begin{array}{l}2018 \\
\text { Q3 }\end{array}$ & $\begin{array}{l}2019 \\
\text { Q3 } \\
\end{array}$ \\
\hline TESLA & 0.057 & 0.14 & 0.354 & 0.692 & 1.007 & 1.601 \\
\hline NISSAN & 0.238 & 0.42 & 0.523 & 0.66 & 0.859 & 0.993 \\
\hline BMW & 0.039 & 0.114 & 0.241 & 0.443 & 0.678 & 0.935 \\
\hline MITSUBISHI & 0.042 & 0.197 & 0.33 & 0.429 & 0.506 & 0.598 \\
\hline OTHER & 0.044 & 0.061 & 0.085 & 0.126 & 0.247 & 0.494 \\
\hline JAGUAR & & & & & 0.027 & 0.331 \\
\hline RENAULT & 0.018 & 0.053 & 0.104 & 0.144 & 0.195 & 0.311 \\
\hline VOLKSWAGEN & 0.005 & 0.017 & 0.038 & 0.062 & 0.143 & 0.246 \\
\hline HYUNDIA & & & & 0.011 & 0.038 & 0.116 \\
\hline AUDI & & 0.009 & 0.016 & 0.025 & 0.034 & 0.103 \\
\hline MERCEDES & & 0.005 & 0.041 & 0.077 & 0.088 & 0.086 \\
\hline TOTAL & 0.443 & 1.016 & 1.732 & 2.669 & 3.822 & 5.8128 \\
\hline
\end{tabular}

Table 1 - Cumulative battery capacity of Plug-In capable Electric Vehicles in UK

\section{Changes in Britain's long-term energy storage}

Taking 2005 as a starting point to consider the changes in stored energy in Britain, Table 1 shows the estimates for the start and end of the 15-year period between 2005 and 2019. All values are approximate to provide an indication of the order of magnitude.

\begin{tabular}{|l|r|r|r|}
\hline \multicolumn{1}{|c|}{ Stored energy in GWh } & \multicolumn{1}{|c|}{2005} & \multicolumn{1}{c|}{2019} & $\begin{array}{r}\text { Difference in } \\
\text { stored energy }\end{array}$ \\
\hline Crude oil and oil products & 170000 & 135000 & -35000 \\
\hline Coal & 125000 & 40000 & -85000 \\
\hline
\end{tabular}




\begin{tabular}{|l|r|r|r|}
\hline Nuclear & 220000 & 160000 & -60000 \\
\hline Natural Gas & 55000 & 31000 & -24000 \\
\hline Biomass & 0 & 3000 & 3000 \\
\hline Electric Vehicle Batteries & 0 & 6 & 6 \\
\hline Pumped storage & 30 & 30 & 0 \\
\hline Total & 570030 & 369036 & -200994 \\
\hline \% of 2005 value & $100 \%$ & $65 \%$ & $35 \%$ \\
\hline
\end{tabular}

Table 2, Changes in stored energy from 2005 to 2019

\section{Discussion}

\section{Why does long-term energy storage exist?}

Energy systems and the storage associated along their supply chains have historically been predicated on the reduction of risk associated with supply chain shocks; of reducing the risk of not having enough energy in the place that it is required when it is required. Storage along supply chains is part of inventory management to decouple supply from demand to help balance supply and demand over different timeframes.

The benefit of long-term storage in reducing supply chain risk can be seen from events such as that shown in Figure 2 when the build-up in coal stocks in 1983 prior to the miners' strike led to the highest level of coal stocks that Britain has ever witnessed. The risk of a supply chain shock had increased, and the amount of coal stocks (which had a cost) was increased to help mitigate this risk. The same principle of reducing the risk of supply chain shocks underpins the premise to have significant and mandated stocks of crude oil and oil products.

In principle, it is possible for non-crude oil and oil products forms of energy to be regulated and mandated to a minimum level, with the costs of this storage passed through and spread out across final consumers. However, policy makers would have to be convinced of the wider merits of an increased cost of energy to consumers by using regulation to promote significant levels of stored energy. This is not done for natural gas or coal or biomass or pumped storage or batteries, it is only for crude oil and oil products.

\section{Reductions in natural gas storage}

The closure of Britain's only long-term storage gas facility in January 2018 (which had been planned for several years) 6-weeks before the severe cold weather event brought the debate surrounding the need for a seasonal gas store into sharp focus with a Gas Storage Parliamentary enquiry (UK Parliament, 2018) later that year. A letter (Perry, 2018) from the then Minister of State for Energy and Clean Growth The Rt Hon Claire Perry MP to the Chair of the BEIS Select Committee provides an insight into arguments and tensions surrounding the need for seasonal storage within a country's own borders. If, as argued implicitly by the letter, an energy market is well served by energy exporting countries' ability to flex deliveries of energy between seasons (e.g. greater energy is delivered in winter than the summer) then having a subsidised seasonal store within a country carries a risk as well as a benefit. This risk was seen as 'undermining the viability of other forms of flexible supply - including faster-cycling gas storage, interconnectors and LNG terminals'. This argument views Britain as a customer of an international supply chain and pre-supposes that other countries will continue to provide energy when needed and that a market rather than a regulatory approach is better placed to provide the amount and type of stored energy. However, if there is a significant natural gas supply disruption, the political imperative to reduce future risks would look very different. 


\section{Cost considerations for long-term storage}

As the data suggests, in 2019 the UK continued to use fuels for its TWh levels of long-term storage. However, as these fuels are fossil fuels they are incompatible with the UK's net-zero target. This presents two main questions; how much long-term energy storage will the UK need in future, and how could this be provided in a manner that is compatible with net-zero targets. Fuels are currently used for this as the combined total cost of the infrastructure and the fuel itself is orders of magnitude lower than other forms of stored energy such as thermal storage or electrochemical methods e.g. batteries or flow batteries.

In future scenarios where the output from weather-dependent electrical generation will need to be stored at a TWh scale to allow for seasonal levels of storage, then this would continue to seem illsuited for batteries due to the cost of storage.

For a future price of $£ 100$ per installed kWh for a complete battery system, the cost for 1 TWh of batteries would be $f 100$ billion. The work from Rathgeber et al., (2015) explored how the acceptable range of capital costs of storage varied against the number of charge discharge cycles in a year and interest rates; this suggests that batteries are ill-suited to seasonal levels of storage due to their capital cost (disregarding any loss of energy over time). Using batteries a low number of times a year for seasonal storage is not a practical way to recoup their initial capital costs. There are other revenue streams that batteries would seek to target, which provide the investment case for their deployment, but seasonal storage is unlikely to be one of these even in the longer term. The cost of battery storage will simply be too expensive in comparison to other forms of storage that are cheaper to store at scale and over longer periods of time.

\section{New drivers for long-term synthetic fuel energy storage}

The historic need for long-term energy storage to provide a buffer against sustained supply chain shocks will still be valid in future energy systems. However, as primary energy sources shift more and more to primary electricity from weather dependent sources such as wind and solar generation, there is a greater opportunity for electrical generation to be in excess of demand at a local, regional and even a national level. The electrical network needs supply and demand to be kept in balance at all times. When supply exceeds demand, either the supply can be decreased or the demand can be increased.

Decreasing the supply may have market costs such as compensating electrical generators to decrease their output. Even when there is no contractual compensation, reducing the supply has an opportunity cost, where the 'excess' electricity in one time period is unavailable to satisfy demand at a future time period.

Increasing demand may take a number of forms such as exporting to other markets through interconnectors or ramping up production processes. The production of hydrogen through electrolysis can be a highly dispatchable and controllable electrical demand to bring balance back to the system; this hydrogen can then be utilised as a fuel itself or used as a feedstock to create a number of other synthetic fuels such as methane, methanol, or ammonia. Regardless of whether batteries in electric vehicles can provide bidirectional support to local networks, they can be effectively utilised as a variable demand that can be controlled up or down. This is also true of thermal energy storage too.

The underlying trend of shifting greater amounts of primary energy to weather dependent renewable generation points to a potential role for synthetic fuels in future energy systems.

This is based on the following assumptions: 
1. There will continue to be a political and market imperative to hold TWhs of energy within national boundaries as an insurance policy against supply chain shocks. These shocks are increasingly influenced by weather events. The TWh scale of the stores of energy will grow significantly after the first major supply shock where imported energy is unable to keep pace with demand at an acceptable price.

2. Times when an electrical market's weather-dependent generation vastly exceeds its demand will become increasingly common. Instantaneous exports through interconnectors continue to be helpful to balance networks, but having significant controllable demand within Britain provides greater levels of flexibility to soak-up excess generation. This could be EV charging, or thermal stores, or electrolysers that create hydrogen and oxygen.

3. The storage of gaseous, liquid or solid fuels continue to be orders of magnitude cheaper than electrochemical storage.

4. Creating low-carbon synthetic fuels not only provides a benefit to Britain in terms of managing its own networks and primary energy over different timeframes, dependent on the type of fuel, it also provides an ability to consider export, or using low-carbon hydrogen as a feedstock to decarbonise other parts of the economy. Low-carbon fertilisers can be used in the farming sector and hydrogen itself (or synthetic methane) can be used to create high-temperature heat for industrial processes.

An energy system that is set up to create TWhs of synthetic fuels is one that is likely to be more robust to supply chain shocks, and have a greater security of supply than one that is dependent on interconnections, and EVs to perform energy system balancing.

International trading of low-carbon energy

An additional benefit of having a system that can produce TWh of synthetic fuels is the possibility of exporting these to other countries as fuels, rather than as electricity. Depending on the cost of the synthetic fuel in comparison to other international producers, this could enable the UK to harness a greater amount of its own natural renewable resource of offshore wind. Development of a synthetic fuel supply chain opens up this as a possibility; without a method to store excess electrical generation at scale, it is unlikely that strategic overinvestment in offshore wind would happen over decades.

The world has to shift away from fossil fuels, but due to the disparity of renewable resource endowments, there will continue to be net energy exporting and net energy importing countries. The development and deployment of synthetic fuel technologies is fundamental to this future, to allow low-carbon energy to be traded internationally, perhaps in a similar manner to the way that fossil fuels are traded today.

\section{The reduction in Britain's long-term stores of energy}

Table 1 points to a 200 TWh reduction in the amount of stored energy within Great Britain's boundaries between 2005 and 2019. We do not attempt to quantify the impact on the security of supply for the country, other than to point out that significant supply chain shocks over the period have been uncommon, as long-term storage has helped to reduce the risk of these; although the $1^{\text {st }}$ of March cold weather event came close. During this period, stocks of coal and natural gas in particular were crucial in keeping energy flowing to end users, with the primary energy demand for the week at around $38 \mathrm{TWh}$ with nearly $80 \%$ provided by natural gas. How much can long-term energy stores continue to be reduced is an open research question, but if the future of storing TWhs of energy is much more expensive than its cost historically, then it is clear that there will be a market pressure to reduce it to a minimum. This needs to be balanced against the political pressure to provide an insurance policy against supply chain shocks. In this sense, there is little difference in principle from the historical political and market-based tension to determine the amounts of longterm stored energy. Whatever the eventual amounts that are felt to be appropriate for an energy 
system basing its primary energy needs predominantly on weather dependent renewable generation, there are benefits of having a system that can create TWhs of synthetic fuels. Some of these could be used quickly, some of these could be stored over the long-term, and some of these could be exported; the point is that there is flexibility to balance the energy system over very different timeframes.

\section{Conclusions}

Policy makers have a difficult role to balance the costs of a system on one hand with the security of an energy system on the other. The risks within supply chains of fossil fuels are historically well known, with unplanned events having a range of impacts. Strike action by people working throughout the fossil fuel sector can have significant consequences, as can infrastructure problems, weather events, wars and major accidents (Thierry Bros, 2018).

However, it is clear that with the change of primary energy sources away from fossil fuels to lower carbon sources, that the types of risk are also changing. Having greater levels of primary energy sourced from renewables that are dependent on the weather brings a different set of risks. Energy systems have always been influenced by the weather in terms of the demand, but weather is increasingly influencing the supply side too.

Over the $20^{\text {th }}$ century, the growth in fossil fuel demand in industrial economies has only been offset by hydro and nuclear generation in providing non-fossil sources of primary energy. However, the first 20 years in the $21^{\text {st }}$ century have seen rapid innovation and deployment in primary electricity generation from solar and wind technologies, which has become a virtuous circle as the capital costs of these technologies have dropped. This has clearly had an effect on the electrical system of Britain, and is about to have an effect on other sectors too, particularly the transport and heat sectors. At less than $2 \%$ of generation in 2019, coal is no longer a significant part of Britain's electrical system, and it is no surprise that the coal stocks have reduced over time too.

It is an open research question regarding how much long-term storage a country such as the UK will continue to need with its future energy systems. This complex question is influenced by political and market forces on the cost of storing energy, the desire to have greater security of supply of energy within national boundaries, and the level of trust and risk associated with external supply chains to be able to deliver energy when required. However, it seems that there are benefits of having a system that can create TWhs of synthetic fuels to help balance future systems over different timeframes to complement other forms of storage such as batteries in Electric Vehicles and thermal storage. 
Amamra, S.-A., Marco, J., 2019. Vehicle-to-Grid Aggregator to Support Power Grid and Reduce Electric Vehicle Charging Cost. IEEE Access 7, 178528-178538. https://doi.org/10.1109/ACCESS.2019.2958664

BEIS, 2019a. Energy Trends: UK oil and oil products. GOV.UK. URL https://www.gov.uk/government/statistics/oil-and-oil-products-section-3-energy-trends (accessed February 2020).

BEIS, 2019b. Digest of UK Energy Statistics (DUKES): solid fuels and derived gases. GOV.UK. URL https://www.gov.uk/government/statistics/solid-fuels-and-derived-gases-chapter-2-digestof-united-kingdom-energy-statistics-dukes (accessed February 2020).

BEIS, 2019c. Energy Trends: UK solid fuels and derived gases. GOV.UK. URL https://www.gov.uk/government/statistics/solid-fuels-and-derived-gases-section-2-energytrends (accessed February 2020).

BEIS, 2019d. Clean energy to power over seven million homes by 2025 at record low prices. GOV.UK. URL https://www.gov.uk/government/news/clean-energy-to-power-over-seven-millionhomes-by-2025-at-record-low-prices (accessed February 2020).

BEIS, 2019e. Contracts for Difference (CfD) Allocation Round 3: results. GOV.UK. URL https://www.gov.uk/government/publications/contracts-for-difference-cfd-allocationround-3-results (accessed February 2020).

BEIS, 2019f. Digest of UK Energy Statistics (DUKES): electricity, Plant loads, demand and efficiency (DUKES 5.10). GOV.UK. URL https://www.gov.uk/government/statistics/electricity-chapter5-digest-of-united-kingdom-energy-statistics-dukes (accessed February 2020).

BEIS, 2019g. Energy Trends: UK electricity. Fuel used in electricity generation and electricity supplied (ET 5.1 - quarterly). GOV.UK. URL https://www.gov.uk/government/statistics/electricitysection-5-energy-trends (accessed February 2020).

BEIS, 2019h. Energy Trends: UK electricity. Electricity production and availability from the public supply system (ET 5.4). GOV.UK. URL https://www.gov.uk/government/statistics/electricitysection-5-energy-trends (accessed February 2020).

BEIS, 2018. DUKES A.1-A.3. GOV.UK. URL https://www.gov.uk/government/statistics/dukes-calorificvalues (accessed February 2020).

Chen, C., Lu, Y., Banares-Alcantara, R., 2019. Direct and indirect electrification of chemical industry using methanol production as a case study. Applied Energy 243, 71-90. https://doi.org/10.1016/j.apenergy.2019.03.184

Chen, H., Cong, T.N., Yang, W., Tan, C., Li, Y., Ding, Y., 2009. Progress in electrical energy storage system: A critical review. Progress in Natural Science 19, 291-312. https://doi.org/10.1016/j.pnsc.2008.07.014

Dawood, F., Anda, M., Shafiullah, G.M., 2020. Hydrogen production for energy: An overview. International Journal of Hydrogen Energy 45, 3847-3869. https://doi.org/10.1016/j.ijhydene.2019.12.059

DECC, 2015. Emergency oil stocking: international obligations. GOV.UK. URL https://www.gov.uk/government/publications/emergency-oil-stocking-internationalobligations (accessed February 2020).

DfT, 2019. All vehicles (VEH01). GOV.UK. URL https://www.gov.uk/government/statistical-datasets/all-vehicles-veh01 (accessed February 2020).

Dodds, P.E., Garvey, S.D., 2016. Chapter 1 - The Role of Energy Storage in Low-Carbon Energy Systems, in: Letcher, T.M. (Ed.), Storing Energy. Elsevier, Oxford, pp. 3-22. https://doi.org/10.1016/B978-0-12-803440-8.00001-4

Drax, 2018. 5 incredible numbers from the world's largest biomass port. Drax. URL https://www.drax.com/technology/5-incredible-numbers-worlds-largest-biomass-port/ (accessed September 2019). 
Drax, 2016. How do you build a dome bigger than the Albert Hall? Drax. URL https://www.drax.com/technology/how-do-you-build-a-dome-bigger-than-the-albert-hall/ (accessed September 2019).

Götz, M., Lefebvre, J., Mörs, F., McDaniel Koch, A., Graf, F., Bajohr, S., Reimert, R., Kolb, T., 2016. Renewable Power-to-Gas: A technological and economic review. Renewable Energy 85, 1371-1390. https://doi.org/10.1016/j.renene.2015.07.066

Kötter, E., Schneider, L., Sehnke, F., Ohnmeiss, K., Schröer, R., 2016. The future electric power system: Impact of Power-to-Gas by interacting with other renewable energy components. Journal of Energy Storage 5, 113-119. https://doi.org/10.1016/j.est.2015.11.012

Lewandowska-Bernat, A., Desideri, U., 2018. Opportunities of power-to-gas technology in different energy systems architectures. Applied Energy 228, 57-67. https://doi.org/10.1016/j.apenergy.2018.06.001

Nayak-Luke, R.M., Bañares-Alcántara, R., 2018. Long-Term Energy Storage: What is the Need and is Ammonia a Solution?, in: Eden, M.R., lerapetritou, M.G., Towler, G.P. (Eds.), Computer Aided Chemical Engineering, 13 International Symposium on Process Systems Engineering (PSE 2018). Elsevier, pp. 1843-1848. https://doi.org/10.1016/B978-0-444-64241-7.50302-5

Noel, L., Papu Carrone, A., Jensen, A.F., Zarazua de Rubens, G., Kester, J., Sovacool, B.K., 2019. Willingness to pay for electric vehicles and vehicle-to-grid applications: A Nordic choice experiment. Energy Economics 78, 525-534. https://doi.org/10.1016/j.eneco.2018.12.014

Nykvist, B., Sprei, F., Nilsson, M., 2019. Assessing the progress toward lower priced long range battery electric vehicles. Energy Policy 124, 144-155. https://doi.org/10.1016/j.enpol.2018.09.035

Perry, C., 2018. Department for Business, Energy \& Industrial Strategy.

Rathgeber, C., Lävemann, E., Hauer, A., 2015. Economic top-down evaluation of the costs of energy storages-A simple economic truth in two equations. Journal of Energy Storage 2, 43-46. https://doi.org/10.1016/j.est.2015.06.001

Thierry Bros, 2018. Reflection on the Baumgarten Gas Explosion.

UK Parliament, 2018. Gas storage inquiry. URL https://www.parliament.uk/business/committees/committees-a-z/commonsselect/business-energy-industrial-strategy/inquiries/parliament-2017/inquiry11/ (accessed February 2020).

Wilson, I.A.G., Staffell, I., 2018. Rapid fuel switching from coal to natural gas through effective carbon pricing. Nature Energy 3, 365. https://doi.org/10.1038/s41560-018-0109-0

Yohe, G., Clarke-Johnson, R., 2019. Balancing Intermittent Renewableswith Europe's Largest Pumped Storage Hydro. American Governor.

Ziegler, M.S., Mueller, J.M., Pereira, G.D., Song, J., Ferrara, M., Chiang, Y.-M., Trancik, J.E., 2019. Storage Requirements and Costs of Shaping Renewable Energy Toward Grid Decarbonization. Joule 3, 2134-2153. https://doi.org/10.1016/j.joule.2019.06.012 